\title{
Optical Microscopy Shared Resource
}

National Cancer Institute

\section{Source}

National Cancer Institute. Optical Microscopy Shared Resource. NCI Thesaurus. Code C39483.

The Optical Microscopy Shared resource provides support for Cancer Center investigators in identification relevant methods for imaging study, and assists researchers with experimental design, image acquisition, training, technical support, and data interpretation. 